\title{
Understanding and Shaping the Athlete's Brain Using Body-Mind Reading and Feedback
}

\author{
Makio Kashino \\ NTT Communication Science Laboratories \\ 3-1, Morinosato Wakamiya, Atsugi, Kanagawa, 243-0198, Japan \\ kashino.makio@lab.ntt.co.jp
}

\begin{abstract}
In sports where athletes play against an opponent, for example, ballgames and martial arts, a variety of cognitive functions hold the key to winning, such as grasping the situation, strategizing against one's opponent, making appropriate decisions instantaneously, and keeping an ideal mental state under intense pressure. Most of these functions, however, are "implicit" brain functions that the athlete himself/herself is not even aware of and cannot control at will. This is thought to be one of the factors behind the difficulty of acquiring, exhibiting, and coaching a specific skill. The NTT Sports Brain Science project was established in January 2017 to conduct research with the aim of understanding superior implicit brain functions in top athletes, identifying the factors in winning, and improving the performance of athletes based on research findings. The technical core of the project is "body-mind reading and feedback", which is constituted by various technologies such as wearable sensing, computer vision, biometric analyses, virtual reality, and sonification. The basic concepts and some research topics of the project will be introduced, with a focus on baseball and softball.
\end{abstract}

\section{CCS Concepts/ACM Classifiers}

- Human-centered computing Human computer interaction

(HCI)

- Applied computing Psychology

- Applied computing Arts and humanities

\section{Author keywords}

Sports; baseball, softball; cognitive neuroscience; implicit brain function; wearable sensing; biometrics; sonification; virtual reality

\section{BIOGRAPHY}

Makio Kashino received his B.A., M.A., and Ph.D. in psychophysics from the University of Tokyo in 1987, 1989, and 2000. He joined NTT as a researcher in 1989. Currently, he is an NTT Fellow / Director of Sports Brain Science Project, NTT Communication Science Laboratories, and a Specially-Appointed Professor in the School of Engineering, Tokyo Institute of Technology.

Using an interdisciplinary research approach bridging cognitive neuroscience and information and communication technology, Dr. Kashino has been studying the functional and neural mechanisms of human cognition, especially auditory perception, cross-modal and sensorimotor interaction, and interpersonal communication, not only in typical people, but also in people with autism spectrum disorder and elite athletes.

\section{REFERENCES}

[1] NTT Sports Brain Science Project http://sportsbrain.ilab.ntt.co.jp/index en.html

[2] "Split seconds matter - the brain and sport," Nature, Vol.549, No.7670, 2017 (advertisement feature).
Permission to make digital or hard copies of part or all of this work for personal or classroom use is granted without fee provided that copies are not made or distributed for profit or commercial advantage and that copies bear this notice and the full citation on the first page. Copyrights for third-party components of this work must be honored. For all other uses, contact the Owner/Author.

MMSports'18, October 26, 2018, Seoul, Republic of Korea.

(C) 2018 Copyright is held by the owner/author(s).

ACM ISBN 978-1-4503-5981-8/18/10.

DOI: https://doi.org/10.1145/3265845.3282351 